\title{
Automatic solid-phase extraction by programmable flow injection coupled to chromatographic fluorimetric determination of fluoroquinolones
}

Patricia S. Peixoto ${ }^{a}$, Eduarda M. P. Silva ${ }^{a}$, Marcelo V. Osório ${ }^{a}$, Luisa Barreiros ${ }^{\mathrm{a}, \mathrm{b}}$, José L.F.C. Lima, Marcela A. Segundo, ${ }^{\text {a, }}$

${ }^{a}$ LAQV, REQUIMTE, Department of Chemical Sciences, Faculty of Pharmacy, University of Porto, R Jorge Viterbo Ferreira, 228, 4050-313 Porto, Portugal.

${ }^{\mathrm{b}}$ NIIF, CISA, School of Allied Health Sciences, Polytechnic Institute of Porto, R Dr. António Bernardino de Almeida, 400 4200-072, Porto, Portugal

* Corresponding author.

Tel.: +351 220428676; Fax: +351226093483

E-mail address: msegundo@ff.up.pt (M.A. Segundo) 


\section{Abstract}

Fluoroquinolones are broad-spectrum bactericidal agents applied for the treatment of human and veterinary diseases. Their common use and their incorrect disposal foster environmental contamination, namely on water resources, increasing the risk of antimicrobial resistance. Hence, a method based on automatic solid-phase extraction coupled to liquid chromatography and fluorimetric detection is proposed for determination of fluoroquinolones in environmental waters. For the solid-phase extraction procedure, commercially available molecularly imprinted polymer targeting fluoroquinolones was trapped inside a flow-through extraction column, integrated in a programmable flow injection system using multisyringe flow injection analysis, where all steps concerning sorbent conditioning, sample loading, matrix removal, and analytes elution were performed under computer control. Eluate resulting from the sample preparation was collected and transferred at-line to chromatographic analysis using a reversed-phase monolithic column coupled to a fluorimetric detector, and isocratic elution with methanol-phosphoric acid ( $\mathrm{pH} 3.0 ; 5.0 \mathrm{mM})(17.5: 82.5$,

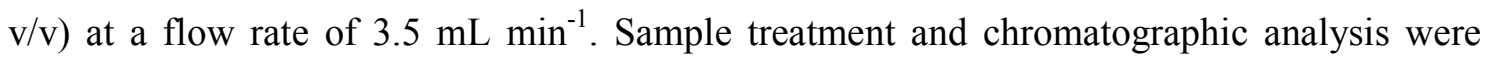
performed in tandem, with sample throughput limited by the sample treatment step. Calibration curves based on fluorescence intensity vs. analyte mass were obtained in the range of 10 to $1000 \mathrm{pg}$ for norfloxacin, ciprofloxacin, and enrofloxacin with LOD values at 6-19 $\mathrm{ng} \mathrm{L}^{-1}$ for a sample volume of $100 \mathrm{~mL}$, and $\mathrm{RSD}<11 \%$ at $0.7 \mu \mathrm{g} \mathrm{\textrm {L } ^ { - 1 }}$. The method was successfully applied to estuarine river water analysis.

Keywords: Programmable flow injection; Monolithic column; Molecularly imprinted polymer; Fluoroquinolone; Environmental water; Multisyringe. 


\section{Introduction}

Antimicrobial agents have been widely used for the treatment of infection diseases. Their residues are continuously discharged into the environment. This situation led to increasing concern about harmful potential effects of antimicrobial residues such as increment of antimicrobial resistance. ${ }^{1}$ This serious public health threat has been an important research target worldwide. Recently, the World Health Organization (WHO) designed a Global Action Plan to fight against increasing of antimicrobial resistance, where several tasks were proposed, including the improvement of strategies for antimicrobial residues monitoring and establishment of standards for controlled use of antimicrobial compounds in agricultural practice. $^{2}$

Fluoroquinolones (FQs) are broad-spectrum bactericidal agents that act by inhibiting the bacterial DNA replication. This antimicrobial class play a crucial role for the treatment of human and veterinary bacterial diseases. ${ }^{3}$ Their slow rates of degradation and their persistence in the aquatic environment can increase the potential for formation of resistance mechanisms and ecotoxicity. ${ }^{1,4} 5$ Moreover, sewage water treatment plants are not able to completely remove these compounds. ${ }^{6,7}$ Thus, determination of these compounds in water is crucial for their environmental risk assessment.

Several strategies for the quantification of FQs in water have been developed. Currently, the gold standard method comprises liquid chromatography coupled to tandem mass spectrometry, ${ }^{8-11}$ while LC coupled to fluorimetric detection is also fitted for purpose due to the intrinsic FQs fluorescence. ${ }^{12-15}$ These techniques provide high sensitivity (low to intermediate $n \mathrm{~L}^{-1}$ level) and selectivity as main features. However, sample pretreatment is frequently necessary in order to eliminate matrix interferences and to foster analyte preconcentration to reach concentrations that can be found in environmental samples. 
Solid phase extraction (SPE) has been widely applied as sample pretreatment of environmental water analysis, ${ }^{16}$ particularly using automatic flow-based schemes. ${ }^{17,}{ }^{18}$ In this context, different polymeric sorbents have been applied for determination of FQs in environmental water samples, such as commercially available polymeric reversed phase Strata ${ }^{\circledR}-X,{ }^{19}, 20$ mixed mode OASIS ${ }^{\circledR}$ HLB ${ }^{21}$, OASIS ${ }^{\circledR}$ WCX for weak cation exchange, ${ }^{10}$ and molecularly imprinted polymers. ${ }^{22-24}$ Silica-based chemically bonded phases has also been applied such as silica-supported graphitic carbon nitride ${ }^{25}$ and graphene-derivatized silica. ${ }^{26}$ More recent approaches have also included the application of boron-enriched divinylbenzene monolith, ${ }^{27}$ mixed hemimicelles based on magnetic $\mathrm{Fe}_{3} \mathrm{O}_{4}$ nanoparticles coated with sodium dodecyl sulfate, ${ }^{28}$ and $\mathrm{ZnO}$-modified methacrylic acid-co-ethylene dimethacrylate polymer monolith ${ }^{29}$ as sorbents. However, sample treatment can be time and reagent consuming, which can limit the sample throughput.

Programmable flow injection analysis can be regarded as the fourth generation of flow injection analysis systems, characterized by computer control of fluidics, allowing the implementation of variable flow rates, stopped flow periods and reversal of flow direction. ${ }^{30-}$ ${ }^{32}$ Multisyringe flow injection analysis (MSFIA) fosters flow injection analysis systems that present as main features: robustness, high flexibility, compatibility with organic solvents, high throughput and multichannel manifolds. ${ }^{33,34}$ MSFIA allows the automation of sample preparation and incorporation of in-line SPE procedures. Thus, sample treatment can be performed with reduction of time and reagents' consumption. ${ }^{35}$ The aim of this work was the development of a sample treatment strategy based on a MSFIA-SPE procedure combined with HPLC-FD for determination of norfloxacin (NOR), ciprofloxacin (CIP) and enrofloxacin (ENR) in environmental water at ng per litre level with enhanced throughput.

\section{Materials and methods}




\section{Reagents and solutions}

All reagents used were of analytical grade and water from arium water purification system (resistivity $>18 \mathrm{M} \Omega \mathrm{cm}$, Sartorius, Goettingen, Germany) was used to prepare aqueous solutions. Norfloxacin (NOR), ciprofloxacin (CIP), and enrofloxacin (ENR) were purchased from Sigma Aldrich (St. Louis, MO, USA). Individual stock standard solutions $\left(1 \mathrm{~g} \mathrm{~L}^{-1}\right)$ of each FQ were stored at $-20{ }^{\circ} \mathrm{C}$ and prepared by weighing the approximate mass of each solid and dissolving it with an aqueous solution of $5.0 \mathrm{mM}$ sulfuric acid. These solutions were filtered and used to prepare an intermediate standard solution $\left(0.1 \mathrm{~g} \mathrm{~L}^{-1}\right)$ by ten times dilution with mobile phase. Working standard solutions used for calibration curves were prepared daily by appropriate dilution of the intermediate standard solution with mobile phase or appropriate solvent.

Chromatographic mobile phase was methanol-phosphoric acid (pH 3.0; $5.0 \mathrm{mM})(17.5: 82.5$, $\mathrm{v} / \mathrm{v}$ ). For mobile phase preparation, firstly, an aqueous solution of phosphoric acid ( $\mathrm{pH} 3.0$; $500 \mathrm{mM}$ ) was prepared by diluting $16.7 \mathrm{~mL}$ of phosphoric acid $1.5 \mathrm{M}$ in $50 \mathrm{~mL}$ of water and by adjusting the $\mathrm{pH}$ to 3.0 using triethylamine (Sigma Aldrich). Then, this solution was diluted $100 \times$ with water to provide the aqueous component of mobile phase, which was further mixed to methanol up to the target proportion. Mobile phase was filtered through HVHP filter $0.45 \mu \mathrm{m}$ from Millipore (Billerica, MA, USA) and degassed using ultrasound radiation for $15 \mathrm{~min}$ prior to usage.

The carrier solution used in the automatic SPE protocol was water. The sorbent conditioning solution, which was also used as the eluent, consisted of methanol-ammonium hydroxide $(98: 2, \mathrm{v} / \mathrm{v})$

Solid-phase extraction phases were acquired from Waters (Milford, MA, USA), including Oasis HLB (200 mg, $30 \mu \mathrm{m}$, cartridge of $6 \mathrm{~mL}$ volume), Oasis MCX (60 mg, $30 \mu \mathrm{m}$, 
cartridge of $3 \mathrm{~mL}$ volume), Oasis WCX (60 $\mathrm{mg}, 30 \mu \mathrm{m}$, cartridge of $3 \mathrm{~mL}$ volume). SupelMIP SPE FQs (25 mg, $57 \mu \mathrm{m}$, and cartridge of $3 \mathrm{~mL}$ volume) from Supelco (Sigma Aldrich) was also acquired.

\section{Chromatographic instrumentation and analysis}

Chromatographic analyses were conducted using a reversed-phase monolithic column (Chromolith RP-18e, $100 \mathrm{~mm} \times 4.6 \mathrm{~mm}$ i.d., Merck, Darmstadt, Germany), connected to a Jasco (Easton, MD, USA) HPLC system (pump PU-2089, autosampler AS-2057 and LC-Net II/ADC controller) coupled to a fluorimetric detector (Jasco FP-2020, $\lambda_{\mathrm{exc}}=280 \mathrm{~nm}, \lambda_{\mathrm{em}}=$ $450 \mathrm{~nm}$ ). Standard and sample solutions were placed into $8 \mathrm{~mm}$ amber glass screw thread vials with flat bottom, which present $1500 \mu \mathrm{L}$ as usable volume, and nominal residual volume $<170 \mu \mathrm{L}(2-\mathrm{SV}(\mathrm{A})$, Thermo Scientific, Waltham, MA, USA). Separation was performed in isocratic mode at a flow rate of $3.5 \mathrm{~mL} \mathrm{~min}^{-1}$, at room temperature $\left(23{ }^{\circ} \mathrm{C}\right)$. Data acquisition and analysis were performed using ChromNAV software (Jasco).

\section{Batch solid-phase extraction procedure}

For sorbent selection, $2 \mathrm{~mL}$ of standard solution containing $100 \mu \mathrm{g} \mathrm{\textrm {L } ^ { - 1 }}$ of each FQ was applied as sample surrogate through each cartridge after the conditioning step. For Oasis sorbents, surrogate sample was prepared in phosphoric acid-triethylamine buffer $(\mathrm{pH} 3.0 ; 5.0$ $\mathrm{mM}$ ) while for Supel-MIP, sample solvent was phosphate buffer ( $\mathrm{pH} 7.2 ; 1.0 \mathrm{mM})$.

For Oasis HLB, cartridges were conditioned with $5 \mathrm{~mL}$ of methanol, followed by $2 \mathrm{~mL}$ of water. Washing was carried out with $5 \mathrm{~mL}$ of water. Finally, FQs were eluted with $3 \times 1 \mathrm{~mL}$ of methanol-phosphoric acid (pH 3.0; $5.0 \mathrm{mM})(98: 2, \mathrm{v} / \mathrm{v})$. Regarding Oasis MCX, sorbent conditioning was performed with $1 \mathrm{~mL}$ of methanol and $1 \mathrm{~mL}$ of water. Washing of sorbent was carried out with $2 \mathrm{~mL}$ of water. The elution was performed with $3 \times 1 \mathrm{~mL}$ of methanol- 
ammonium hydroxide $(98: 2, \mathrm{v} / \mathrm{v})$. Concerning Oasis WCX extraction, the sorbent was conditioned with $1 \mathrm{~mL}$ of methanol and $1 \mathrm{~mL}$ of water. A volume of $2 \mathrm{~mL}$ of water was applied as washing step. Elution was performed with $3 \times 1 \mathrm{~mL}$ of methanol-formic acid (98:2, v/v). MIP sorbent was conditioned with $1 \mathrm{~mL}$ of methanol and $2 \mathrm{~mL}$ of water. The washing step was carried out with $2 \times 3 \mathrm{~mL}$ of water. At last, FQs were eluted with $3 \times 1 \mathrm{~mL}$ of methanol-ammonium hydroxide $(98: 2, \mathrm{v} / \mathrm{v})$.

\section{MSFIA equipment and automatic extraction procedure}

Water and eluent were propelled into the system by a multisyringe burette (Crison Instruments, Allela, Spain), equipped with syringes of $10 \mathrm{~mL}$ and $5 \mathrm{~mL}$ placed in positions 2 and 3, respectively. Three-way commutation valves (NResearch, Caldwell, NJ, USA) were connected to the head of each syringe and four extra commutation valves were connected into the system, controlled through the burette with permutations classified in "on" or "off" lines. A personal computer, running lab-made software written in QuickBasic 4.5 (Microsoft, Redmond, WA, USA), controlled the number of steps, the position of all commutation solenoid valves and direction of piston displacement.

Samples were loaded into the solid-phase column using a Minipuls 3 peristaltic pump (Gilson, Villiers-le-Bel, France) equipped with polyvinylchloride pumping tubes. Flow direction and rotation speed were also controlled through a dedicated software using a PCL818 interface card (Advantech, Taipei, Taiwan).

The different components of the flow-system were disposed as shown schematically in Fig, 1. All connections were made with $0.8 \mathrm{~mm}$ i.d. polytetrafluorethylene tubing (Omnifit, Cambridge, UK). A lab-made polyetheretherketone extraction column was used. This column presented a tubular configuration with $24 \mathrm{~mm}$ of length and $3 \mathrm{~mm}$ of internal diameter, 
containing $c a$. $100 \mathrm{mg}$ of sorbent. The sorbent was trapped inside the column by filter disks from MoBiTec (Goettingen, Germany) with pore diameter of $35 \mu \mathrm{m}$.

The protocol sequence adopted for the automatic solid-phase extraction of FQs is described in Table 1. The complete sequence included seven steps. Initially, $3500 \mu \mathrm{L}$ of methanolammonium hydroxide $(98: 2, \mathrm{v} / \mathrm{v})$ were propelled through the sorbent bed, by switching valve V3 on (step 1). After commutation of the suitable valves, including switching V2 on and V3

off, sorbent conditioning was performed with $2500 \mu \mathrm{L}$ of water (step 2). Afterwards, with all valves in "off" position, the peristaltic pump was activated and the selected sample volume was sent through the extraction column at $4.0 \mathrm{~mL} \mathrm{~min}^{-1}$ (step 3). After refilling the syringes (step 4), the sorbent column was percolated with $2500 \mu \mathrm{L}$ of water for sample matrix removal by switching valve V2 on (step 5). Then, a volume of $1500 \mu \mathrm{L}$ of methanol-ammonium hydroxide $(98: 2, \mathrm{v} / \mathrm{v})$ was used for elution of retained compounds (valve V2 switched off, valve V3 switched on, step 6) and eluate was collected to an eppendorf tubing. Ultimately, the syringes were refilled, with both valves V2 and V3 switched off, connecting syringes to water and eluent reservoirs, respectively (step 7). Prior to chromatographic analysis, eluate was diluted $5 \times$ with $500 \mathrm{mM}$ phosphoric acid.

\section{Sample collection}

Water sample from the Douro River estuary was collected at low tide using $1 \mathrm{~L}$ acid-cleaned polyethylene bottles. The sample was filtered through $1.2 \mu \mathrm{m}$ glass microfiber filters (VWR International, Leuven, Belgium) followed by $0.22 \mu \mathrm{m}$ Millipore GVWP filters, and analyzed after $\mathrm{pH}$ adjustment at 7.2.

\section{Results and discussion}




\section{Selection of chromatographic conditions}

The net charge of the target FQs in this study depends on $\mathrm{pH}$ as featured in Fig. S1-S3 (Electronic Supplementary Information). Up to $\mathrm{pH} 4$, net charge is positive from protonation of amine group in piperazine ring. For $\mathrm{pH}$ values above 10 (or 8 for ENR), net charge is negative from proton loss in the carboxylic group attached to quinolone moiety. For $\mathrm{pH}$ values between 6 and 8 , NOR and CIP have similar behaviour, with neutral net charge from protonation of amine group in piperazine ring and proton loss in the carboxylic group to quinoline moiety. ENR has different features in this $\mathrm{pH}$ region, showing prevalence of neutral net charge (ca. $65 \%$ of total species) at $\mathrm{pH} 6$ from two species: one bearing positive charge at a tertiary amine in the piperazine ring and a negative charge at the carboxylic group, while the other species does not have any ionized group. This difference in behaviour from the other two target FQs prompt the choice of a lower $\mathrm{pH}$ for the mobile phase, securing that all FQs would be in a similar ionized form. Higher $\mathrm{pH}$ values $(>10)$ were not considered because of column susceptibility. Hence, the aqueous component of mobile phase was set as phosphoric acid-triethylamine ( $\mathrm{pH} 3.0 ; 5 \mathrm{mM})$.

In order to achieve fast separation, a C18 monolithic column was chosen. Mobile phase composition, using methanol as organic modifier, and flow rate were studied, as summarized in Fig. S4 and S5. Results revealed that methanol at $17.5 \%(\mathrm{v} / \mathrm{v})$ provided the shortest run time necessary to elute the target FQs without compromising peak separation. Considering that monolithic columns do not present back-pressure problems when increasing mobile phase flow rate, this parameter was evaluated up to $5.0 \mathrm{~mL} \mathrm{~min}^{-1}$. Chromatograms obtained using a $10 \mathrm{mg} \mathrm{L}^{-1} \mathrm{FQs}$ standard showed that $3.5 \mathrm{~mL} \mathrm{~min}^{-1}$ was the highest flow rate that allowed good separation of target FQs in a relatively short time (about 4 min), with NOR retention time of $2.2 \mathrm{~min}$, CIP retention time of $2.5 \mathrm{~min}$ and ENR retention time of $3.0 \mathrm{~min}$. 
Under the above mentioned optimum working conditions, the sampling rate achieved was 7.5 $\mathrm{h}^{-1}$.

In order to establish a dynamic concentration range based on FQ mass, analysis of standards

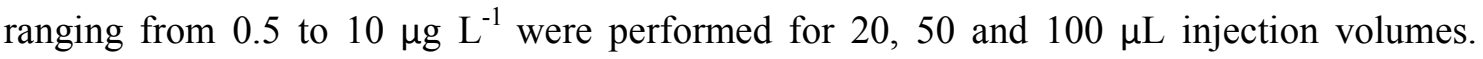
Fluorescence intensity $v s$. analyte mass calibration curves were obtained in the range of 10 to 1000 pg, providing $y=(2669 \pm 14) x-961 \pm 4535$ for NOR, $y=(2162 \pm 12) x+3555 \pm$ 4008 for CIP, and $y=(3990 \pm 29) x+8271 \pm 9200$ for ENR, $n=27, \mathrm{R}>0.9993$. Therefore, when results were plotted for each injection volume, direct proportionality was obtained, i.e. slopes were 5 times higher for $100 \mu \mathrm{L}$ injection volume, when compared to $20 \mu \mathrm{L}$ injection volume. Thus, injection volume selection can be tailored according to FQs expected level between $100 \mathrm{ng} \mathrm{L}^{-1}$ and $50 \mu \mathrm{g} \mathrm{L}^{-1}$, with a dynamic mass range of 10-1000 pg.

Compared to previously reported methods using fluorimetric detection, this analytical range surpasses the state-of-the-art, allowing a reduction of $>\operatorname{ten}^{36}$ to two ${ }^{10}$ times concerning the lowest quantifiable mass. These features were attained due to the combination of monolithic column to large sample injection volume (up to $100 \mu \mathrm{L}$ ).

\section{Selection of sorbent for the SPE procedure}

Once defined the conditions for the chromatographic determination, the next step was the selection of sorbent. Four different SPE sorbents with different physico-chemical characteristics were evaluated, comprising commercially available polymeric materials. Molecularly imprinted polymer (Supel-MIP) and hydrophilic-lipophilic balance co-polymers, bearing retention mechanisms based on reversed-phase (Oasis HLB) or based on both reversed-phase and cation exchange (Oasis MCX and Oasis WCX) were tested under conventional conditions as recommended by suppliers. Standards containing $100 \mu \mathrm{g} \mathrm{L}^{-1}$ of each FQ were acidified for retention in the hydrophilic-lipophilic balance co-polymers, 
providing analytes with positive charge. For MIP experiments, standard $\mathrm{pH}$ was adjusted to 7.2, originating the zwitteronic form of NOR and CIP (Fig. S1 and S2), while ENR was mainly negatively charged, with a lower presence of its zwitteronic form.

Results concerning analyte recovery are depicted in Fig. 2. Extraction with the weak cationexchanger Oasis WCX did not provide analyte recovery. Better results were attained for the MIP sorbent, providing values between 74.6 and $95.6 \%$ for target analytes. Better recoveries with MIP sorbent can be related with their higher selectivity to an analyte or structurally related molecules, which allows a better analytical performance when compared to other sorbents. $^{23,24,37}$ In this way, MIPs sorbent were selected for further experiments.

\section{Development of automatic MSFIA-SPE system}

The application of programmable flow present valuable features, such as low consumption of sample and reagent, precise control of solutions' volume and flow rate, and compatibility with organic solvents when MSFIA systems are employed. Furthermore, a peristaltic pump was included to the MSFIA basic manifold in order to handle large sample volumes (up to $100 \mathrm{~mL}$ ) commonly required in environmental analysis. The sample loading and the elution step were established in counter-current in order to avoid cumulative pressure into the extraction column. Hence, the microcolumn was inserted between two commutation valves (Fig. 1, V5-V7). The length of the tubing in the exit of the extraction column was shorter as possible in order to avoid dilution due to dispersion of the extracted analytes. Valve V8 (Figure 1) was introduced between valve V6 and the SPE column (V7-V5) to prevent the contamination of the extraction column upon change of sample or standard solutions.

Flow rate of sample loading was evaluated, in order to minimize the time required for pretreatment of large sample volumes. This study was carried out by loading $5 \mathrm{~mL}$ of phosphate buffer ( $\mathrm{pH} 7.2 ; 1 \mathrm{mM}$ ) containing $10 \mu \mathrm{g} \mathrm{\textrm {L } ^ { - 1 }}$ of each FQ compound at flow rates in 
the range of $0.5-4 \mathrm{~mL} \mathrm{~min}^{-1}$. Elution was performed by loading $610 \mu \mathrm{L}$ of methanolammonium hydroxide $(98: 2, \mathrm{v} / \mathrm{v})$. Similar recoveries were attained at any tested flow rate, with mean values of $42.6 \pm 3.5 \%$ (NOR), $43.5 \pm 3.5 \%$ (CIP), and $39.6 \pm 4.0 \%$ (ENR). Hence, the flow rate of $4 \mathrm{~mL} \min ^{-1}$ was selected to maximize throughput. A similar study was performed to evaluate the elution flow rate $\left(0.5-1.5 \mathrm{~mL} \mathrm{~min}^{-1}\right)$. Also, similar recoveries were attained for all tested flow rates, with mean values of $35.6 \pm 0.8 \%$ (NOR), $37.2 \pm 0.9 \%$ (CIP), and $31.5 \pm 1.1 \%$ (ENR). Therefore, the flow rate of $1.5 \mathrm{~mL} \mathrm{~min}{ }^{-1}$ was adopted to perform the elution step.

The eluent volume is also a critical aspect in flow-based SPE procedures as depicted in Fig. 3. The elution profile was evaluated for eluent volumes between 600 and $1750 \mu \mathrm{L}$. As expected, the elution profile regarding the concentration of FQs in eluate increased with the applied volume up to a value $(1500 \mu \mathrm{L})$ where a dilution effect was observed for higher eluent volumes. This means that applied elution conditions could not foster more analyte desorption. This is corroborated when expressing the results as recovered mass, where a stable value was reached for volumes equal or higher than $1500 \mu \mathrm{L}$.

Next, the effect of loading volume on analyte recovered mass was studied by passing the same amount ( $50 \mathrm{ng}$ of each FQ) through the SPE column using volumes between 5 and 100 $\mathrm{mL}$. Similar recoveries were attained for 5 and $10 \mathrm{~mL}$ (ranging from $56.2 \pm 0.2 \%$ and $69.4 \pm$ $0.5 \%)$, while lower recovery values were obtained for 25 (41.1-66.0\%), 50 (31.7-66.2\%), and $100 \mathrm{~mL}(21.3-56.1 \%)$ of sample loading volume. As recoveries above $85 \%$ were not reached and considering the non-equilibrium yet reproducible features of programmable-flow systems, calibration under the same extraction conditions concerning sample volume, loading and elution conditions is recommended for application to samples. 
The analytical performance of the MSFIA-SPE system was evaluated considering the limits of detection (LOD) and quantification (LOQ), determination frequency, repeatability, accuracy, and applicability to real samples. ${ }^{38}$ Values of LOD and LOQ were established as 6 to $19 \mathrm{ng} \mathrm{L}^{-1}$ and $17-51 \mathrm{ng} \mathrm{L}^{-1}$, respectively, considering a sample loading volume of $100 \mathrm{~mL}$ (detailed information for each compound is given in Table S1). As sample treatment and HPLC analysis can be performed in tandem (one sample is run in HPLC while the following sample is processed at MSFIA-SPE), the time taken for analyzing each sample was conditioned by the slowest process. Hence, for the sample loading volume of $100 \mathrm{~mL}$, the determination frequency was 2 determinations per hour, established by 31.3 min required for MSFIA-SPE procedure. Sample throughput can be increased up to $6.7 \mathrm{~h}^{-1}$ if a lower sample volume $(10 \mathrm{~mL}$, for instance) is applied. Sample volumes $<7.5 \mathrm{~mL}$ are not recommended as no preconcentration will occur because the eluate is diluted 5 times after collection to avoid band broadening effects in the chromatographic run. Repeatability was established using 0.7 $\mu \mathrm{g} \mathrm{L}^{-1}$ standard, providing RSD values of 9.0, 11, and 3.7\% for norfloxacin, ciprofloxacin, and enrofloxacin, respectively $(n=4)$. These values are acceptable considering the concentration level tested because, according to the Horwitz function, there is a tendency for an invariant RSD of about $20-25 \%$ for concentrations below $10 \mathrm{ppb}$ ( $\mu \mathrm{g}$ per litre). ${ }^{39}$ Accuracy was evaluated through back-calculated concentrations ranging from $300 \mathrm{ng} \mathrm{L}^{-1}$ to $1.50 \mu \mathrm{g} \mathrm{L}^{-1}$, using sample volume of $10 \mathrm{~mL}$. Values were within the interval $94.5-113.2 \%$ for the target concentrations, demonstrating the method accuracy.

Douro River sample was analyzed by the proposed MSFIA-SPE-HPLC method. Values of 42 $\pm 3,<\mathrm{LOQ}$ (26), and $64 \pm 1 \mathrm{ng} \mathrm{\textrm {L } ^ { - 1 }}$ were found for norfloxacin, ciprofloxacin, and enrofloxacin, respectively. The proposed method showed to be suitable for reaching low ng $\mathrm{L}^{-1}$ values required for environmental analysis. 
Compared to previously reported method, comprising flow-based and online sample treatment, the proposed method presents advantageous features, namely the higher sample throughput. In fact, the method comprising online preconcentration of $15 \mathrm{~mL}$ of sample required $10 \mathrm{~min}$ for this operation, and the chromatographic run took $18 \mathrm{~min} .{ }^{40}$ When these operations were performed in tandem, ${ }^{41}$ it still required more than half an hour for analyzing one sample. In the proposed method, samples can be prepared and analyzed in tandem using an at-line approach. ${ }^{17}$ This means that eluates are collected and immediately transferred to HPLC autosampler. Online hyphenation could have been implemented as described before for other analytes ${ }^{17,18}$ but, as HPLC analysis was performed in 4 min and MSFIA-SPE would take between 9 and $31 \mathrm{~min}$, tandem operation would mean a waste of chromatographic eluent and unnecessary occupation of HPLC equipment. Hence, samples were extracted during the day and run in HPLC overnight to avoid wasteful operation. Using this approach, sample throughput is enhanced to 54 sample/day, considering an 8 hours working day.

\section{Conclusions}

A novel automatic flow-based procedure that combines sample pre-treatment with reversedphase HPLC analysis for the determination of fluoroquinolones (NOR, CIP and ENR) in water has been successfully developed. Automation of sample treatment allows the strict control of solid-phase extraction parameters, namely flow rates applied in each step of this procedure using programmable flow through multisyringe flow injection analysis. Application of the proposed method to river estuarine water was performed successfully. The achieved LOD values and the enhanced throughput procedure allows the fast analysis of fluoroquinolones using a fit for purpose method, tailored for environmental analysis requiring a large number of sampling points. 


\section{Acknowledgements}

This work was supported by the European Union (FEDER funds) and National Funds (FCT/MEC, Fundação para a Ciência e Tecnologia and Ministério da Educação e Ciência) under the Partnership Agreement PT2020 UID/QUI/50006/2013 POCI/01/0145/FEDER/007265; P. Peixoto thanks CAPES, Ciência sem Fronteiras program (BEX 9532/13-7), and L. Barreiros thanks FCT (Fundação para a Ciência e a Tecnologia) for her Post-Doc (SFRH/BPD/89668/2012). E. M. P. Silva acknowledges funding from FEDER Operational Competitiveness and Internationalization Program (COMPETE 2020) through project NORTE-01-0145-FEDER-000011. 


\section{References}

1 D. Morris, S. Harris, C. Morris, E. Cummins and M. Cormican, Hospital effluent: impact on the microbial environment and risk to human health (2008-EH-MS-6-S3) 978-1-84095-614-6, Environmental Protection Agency, Wexford, Ireland, 2015.

2 FAO, The FAO Action Plan on Antimicrobial Resistance 2016-2020, Food and Agriculture Organization of The United Nations, Rome, 2016.

3 N. Janecko, L. Pokludova, J. Blahova, Z. Svobodova and I. Literak, Environ Toxicol Chem, 2016, 35, 2647.

4 P. Sukul and M. Spiteller, in Reviews of Environmental Contamination and Toxicology, eds. G. Ware, H. Nigg and D. Doerge, Springer, New York, 2007, vol. 191, pp. 131.

5 G. McEneff, W. Schmidt and B. Quinn, Pharmaceuticals in the Aquatic Environment: A Short Summary of Current Knowledge and the Potential Impacts on Aquatic Biota and Humans (EPA Research Report 142) 978-1-84095-579-8, Environmental Protection Agency, Wexford, Ireland, 2015.

6 E. M. Golet, I. Xifra, H. Siegrist, A. C. Alder and W. Giger, Environ. Sci. Technol, $2003,37,3243$.

7 M. Bergheim, R. Gminski, B. Spangenberg, M. Debiak, A. Bürkle, V. MerschSundermann, K. Kümmerer and R. Gieré, Environ. Sci. Pollut. Res., 2015, 22, 18017.

8 M. Bourdat-Deschamps, S. Leang, N. Bernet, J. J. Daudin and S. Nelieu, J. Chromatogr. A, 2014, 1349, 11.

9 A. Speltini, M. Sturini, F. Maraschi, S. Viti, D. Sbarbada and A. Profumo, J. Chromatogr. A, 2015, 1410, 44.

10 K. He and L. Blaney, J. Hazard. Mater., 2015, 282, 96. 
11 M. Lombardo-Agui, C. Cruces-Blanco, A. M. Garcia-Campana and L. Gamiz-Gracia, J. Sep. Sci., 2014, 37, 2145.

12 A. Pena, D. Chmielova, C. M. Lino and P. Solich, J. Sep. Sci., 2007, 30, 2924.

13 E. Benito-Pena, S. Martins, G. Orellana and M. C. Moreno-Bondi, Anal. Bioanal. Chem., 2009, 393, 235.

14 S. Montesdeoca-Esponda, Z. Sosa-Ferrera and J. J. Santana-Rodríguez, J. Liq. Chromatogr. Relat. Technol., 2012, 352081.

15 N. Arroyo-Manzanares, J. F. Huertas-Perez, M. Lombardo-Agui, L. Gamiz-Gracia and A. M. Garcia-Campana, Anal. Methods, 2015, 7, 253.

16 A. Andrade-Eiroa, M. Canle, V. Leroy-Cancellieri and V. Cerdà, Trac-Trends Anal. Chem., 2016, 80, 655.

17 M. Miro, H. M. Oliveira and M. A. Segundo, Trac-Trends Anal. Chem., 2011, 30, 153.

18 H. M. Oliveira, M. A. Segundo, J. L. F. C. Lima, M. Miro and V. Cerda, J. Chromatogr. A, 2010, 1217, 3575.

19 M. Gbylik-Sikorska, A. Posyniak, T. Sniegocki and J. Zmudzki, Chemosphere, 2015, $119,8$.

20 P. Paiga, L. H. Santos and C. Delerue-Matos, J. Pharm. Biomed. Anal., 2017, 135, 75.

21 B. Prutthiwanasan, C. Phechkrajang and L. Suntornsuk, Talanta, 2016, 159, 74.

22 E. Rodriguez, F. Navarro-Villoslada, E. Benito-Pena, M. D. Marazuela and M. C. Moreno-Bondi, Anal. Chem., 2011, 83, 2046.

23 A. Prieto, S. Schrader, C. Bauer and M. Moeder, Anal. Chim. Acta, 2011, 685, 146.

24 E. Benito-Pena, J. L. Urraca, B. Sellergren and M. Cruz Moreno-Bondi, J. Chromatogr. A, 2008, 1208, 62. 
25 A. Speltini, F. Maraschi, R. Govoni, C. Milanese, A. Profumo, L. Malavasi and M. Sturini, J. Chromatogr. A, 2017, 1489, 9.

26 A. Speltini, M. Sturini, F. Maraschi, L. Consoli, A. Zeffiro and A. Profumo, J. Chromatogr. A, 2015, 1379, 9.

27 M. Mei and X. J. Huang, J. Sep. Sci., 2016, 39, 1908.

28 L. Wang, Q. X. Yuan, G. X. Liang, L. B. Shi and Q. Zhan, J. Sep. Sci., 2015, 38, 996.

29 D. Liu, J. T. Ma, Y. Jin, X. Q. Li, X. A. Zhou, Q. Jia and W. H. Zhou, J. Sep. Sci., 2015, 38, 134.

30 J. Ruzicka, Talanta, 2016, 158, 299.

31 V. Manzo, M. Miro and P. Richter, J. Chromatogr. A, 2014, 1368, 64.

32 I. I. Ramos, B. J. R. Gregorio, L. Barreiros, L. M. Magalhaes, I. V. Toth, S. Reis, J. L. F. C. Lima and M. A. Segundo, Talanta, 2016, 150, 599.

33 V. Cerdà, J. Avivar and A. Cerdà, Pure Appl. Chem., 2012, 84, 1983.

34 M. A. Segundo and L. M. Magalhaes, Anal. Sci., 2006, 22, 3.

35 F. Maya, J. M. Estela and V. Cerdà, Spectr. Lett., 2009, 42, 312.

36 E. M. Golet, A. C. Alder, A. Hartmann, T. A. Ternes and W. Giger, Anal. Chem., $2001,73,3632$.

37 L. Chen, X. Zhang, Y. Xu, X. Du, X. Sun, L. Sun, H. Wang, Q. Zhao, A. Yu, H. Zhang and L. Ding, Anal. Chim. Acta, 2010, 662, 31.

38 J. N. Miller, J. C. Miller, Statistics and Chemometrics for Analytical Chemistry, $5^{\text {th }}$ ed. Pearson Education Ltd, Harlow, 2005.

39 Statistical Subcommittee of the Analytical Methods Committee - Royal Society of Chemistry, The amazing Horwitz function, AMC Technical Brief No.17, 2004, http://www.rsc.org/images/horwitz-function-technical-brief-17_tcm18-214859.pdf, accessed on 02/04/2018. 
40 M. D. G. Garcia, A. B. Gallegos, R. S. Valverde and M. M. Galera, J. Sep. Sci., 2012, 35,823 .

41 F. J. Lara, M. del Olmo-Iruela and A. M. Garcia-Campana, J. Chromatogr. A, 2013, $1310,91$. 


\section{Figure captions}

Figure 1 MSFIA-SPE manifold for automatic extraction of fluoroquinolones prior to HPLC analysis. MS, multisyringe; $\mathrm{S} i$, syringe; $\mathrm{V} i$, commutation valves; SPE, microcolumn containing MIP sorbent; PP, peristaltic pump; W, waste; S2, $10 \mathrm{~mL}$ syringe; S3, $5 \mathrm{~mL}$ syringe; $\mathrm{S}$, sample or standard solution. Eluent is methanol-ammonium hydroxide $(98: 2, \mathrm{v} / \mathrm{v})$. In the solenoid valves, the position "on" is depicted by a solid line while the position "off" is depicted by a dotted line. Valves V1 and V4 were not used (represented in light grey).

Figure 2 Extraction efficiencies using different SPE sorbents, placed in conventional cartridges. NOR, white bar; CIP, black bar; and ENR, grey bar. Results for Oasis WCX are not presented as any analyte was recovered.

Figure 3 Elution profile regarding FQs concentration in eluate and recovered FQs mass using different volumes of eluent (methanol-ammonium hydroxide $(98: 2, \mathrm{v} / \mathrm{v}))$. NOR, white bar; CIP, black bar; and ENR, grey bar. Loaded sample: $5 \mathrm{~mL}$ of phosphate buffer $(\mathrm{pH} 7.2 ; 1$

$\mathrm{mM}$ ) containing $10 \mu \mathrm{g} \mathrm{L}^{-1}$ of each fluoroquinolone. 
Table 1 Protocol sequence for the automatic solid-phase extraction of fluoroquinolones from water.

\begin{tabular}{|c|c|c|c|c|c|c|c|c|c|c|c|}
\hline \multirow[b]{2}{*}{ Step } & \multirow[b]{2}{*}{ Description } & \multicolumn{8}{|c|}{ Position of the commutation valves ${ }^{b}$} & \multirow[b]{2}{*}{ Time / s } & \multirow{2}{*}{$\begin{array}{c}\text { Volume / } \\
\mu L^{\mathrm{c}}\end{array}$} \\
\hline & & 1 & 2 & 3 & 4 & 5 & 6 & 7 & 8 & & \\
\hline 1 & Sorbent bed is washed with methanol-ammonia $(98: 2, \mathrm{v} / \mathrm{v})$ & - & $\mathrm{F}$ & $\mathrm{N}$ & - & $\mathrm{N}$ & - & $\mathrm{N}$ & - & 70 & 7000 \\
\hline 2 & Water is sent through the column for sorbent conditioning & - & $\mathrm{N}$ & $\mathrm{F}$ & - & $\mathrm{F}$ & $\mathrm{F}$ & $\mathrm{F}$ & $\mathrm{F}$ & 50 & 2500 \\
\hline 3 & $\begin{array}{l}\text { Sample is loaded to the preconcentration column where } \\
\text { analytes retention take place }{ }^{\mathrm{a}}\end{array}$ & - & $\mathrm{F}$ & $\mathrm{F}$ & - & $\mathrm{F}$ & $\mathrm{N}$ & $\mathrm{F}$ & $\mathrm{F}$ & $75-1500$ & $X^{\mathrm{d}}$ \\
\hline 4 & Syringes are refilled & - & $\mathrm{F}$ & $\mathrm{F}$ & - & - & - & - & - & 55 & 5500 \\
\hline 5 & Water is sent through the column for matrix removal & - & $\mathrm{N}$ & $\mathrm{F}$ & - & $\mathrm{F}$ & $\mathrm{F}$ & $\mathrm{F}$ & $\mathrm{F}$ & 50 & 2500 \\
\hline 6 & $\begin{array}{l}\text { Methanol-ammonia }(98: 2, v / v) \text { is sent through the column, } \\
\text { eluting the retained analytes, eluate is collected }\end{array}$ & - & $\mathrm{F}$ & $\mathrm{N}$ & - & $\mathrm{N}$ & - & $\mathrm{N}$ & - & 60 & 3000 \\
\hline 7 & Syringes are refilled & - & $\mathrm{F}$ & $\mathrm{F}$ & - & - & - & - & - & 95 & 9500 \\
\hline
\end{tabular}

${ }^{a}$ The peristaltic pump is activated $\left(4 \mathrm{~mL} \mathrm{~min}^{-1}\right)$ during the time required to propel the selected sample volume.

${ }^{\mathrm{b}} \mathrm{N}$ and F position corresponds to "on" and "off", respectively.

${ }^{\mathrm{c}}$ The referred values of volumes are based on syringe $2(10 \mathrm{~mL})$.

${ }^{\mathrm{d}}$ Variable volume up to $100 \mathrm{~mL}$. 


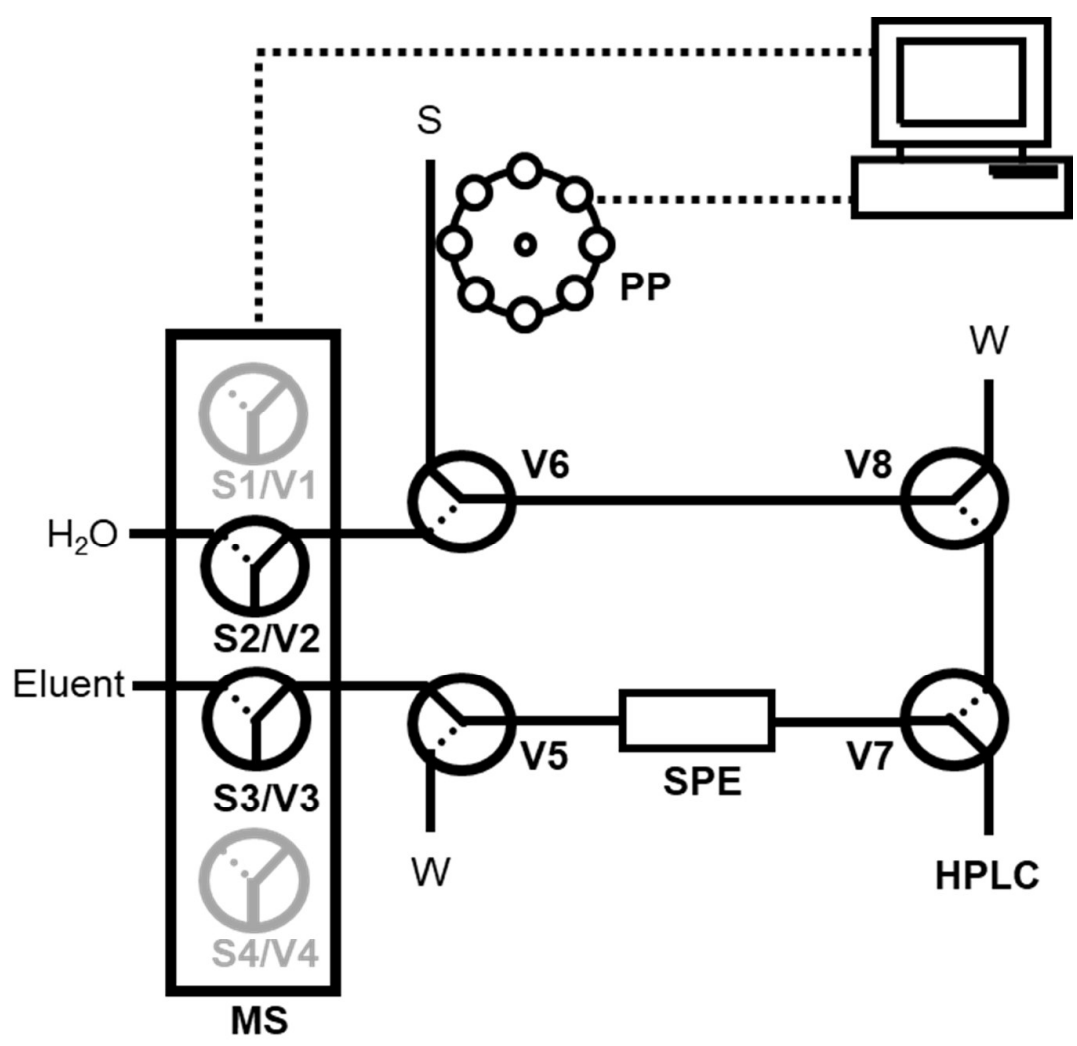

Figure 1 


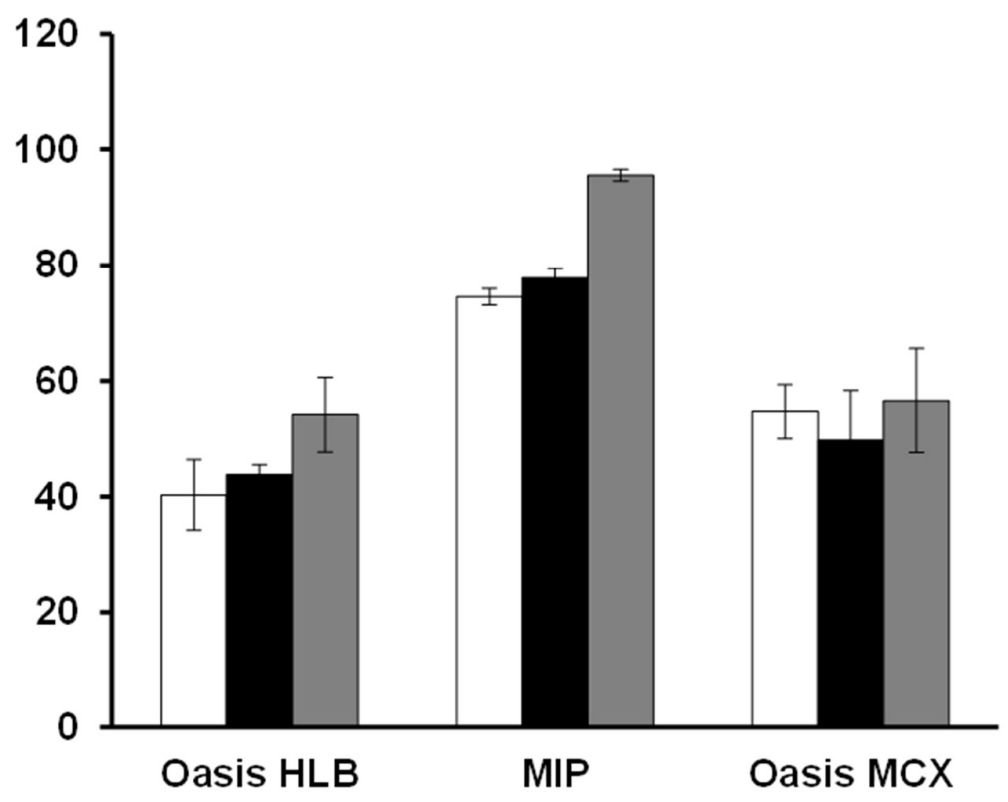

Figure 2 

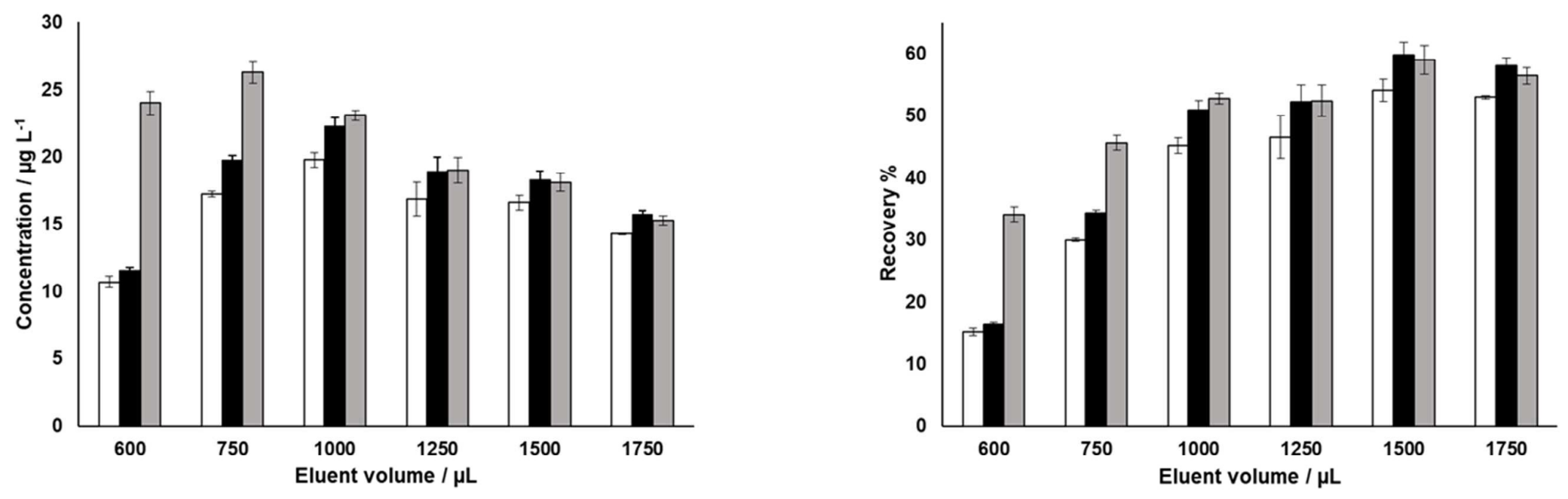

Figure 3 


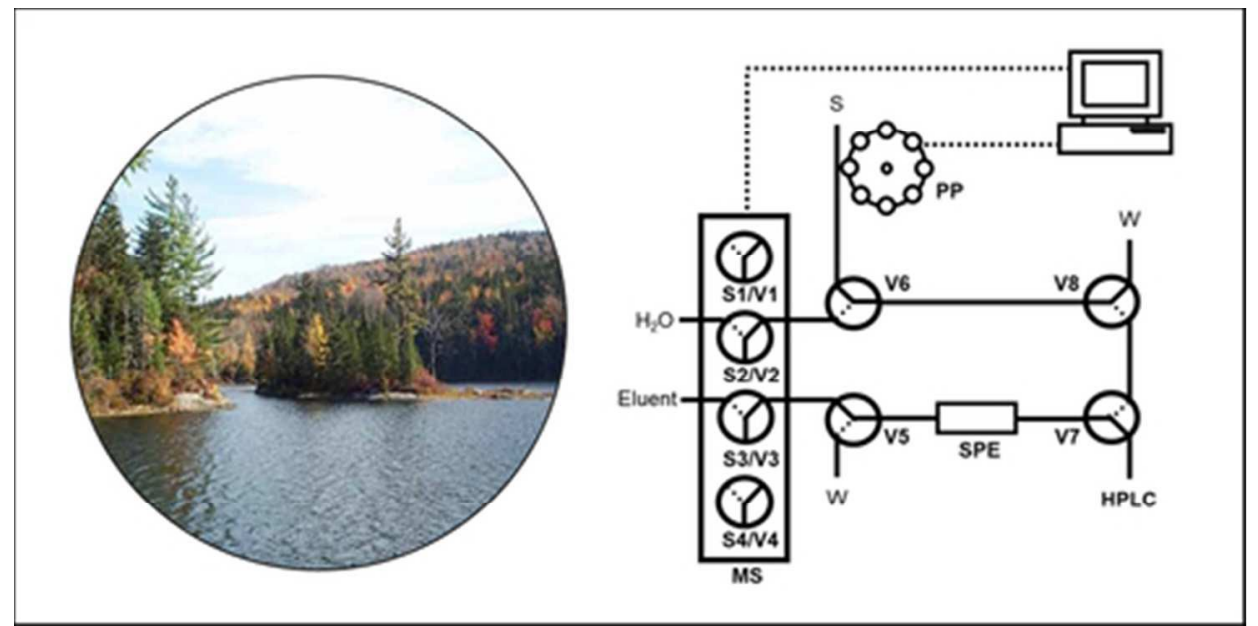

Automatic sample preparation for extraction and preconcentration of fluoroquinolones in environmental waters

$40 \times 20 \mathrm{~mm}(300 \times 300 \mathrm{DPI})$ 